\title{
O QUE CINDERELA E A BELA E A FERA TÊM A VER COM A GEOGRAFIA?
}

\author{
Jacqueline Praxedes de Almeida ${ }^{1}$ \\ Denis Rocha Calazans ${ }^{2}$
}

\section{RESUMO}

O uso de paradidáticos nas aulas de Geografia ajuda a promover a interdisciplinaridade, além de possibilitar o estímulo ao senso crítico e a ampliação dos conhecimentos. Nesse sentido, foi introduzido na disciplina de Metodologia do Ensino de Geografia, no curso de Licenciatura em Geografia, o trabalho com obras literárias, mais especificamente os contos infantis, sendo eles lidos e pensados na perspectiva do trabalho com conteúdos referentes ao 2 o ano do Ensino Médio. A atividade desenvolvida teve como objetivo proporcionar aos licenciandos bases para promover a integração entre Literatura e Geografia. O desenvolvimento da atividade mostrou, dentre outros resultados, que a maioria não tinha pensado em utilizar contos infantis nas aulas de Geografia e que, após a execução da atividade, adotariam essa prática durante as aulas.

Palavras-chave: Formação docente. Livros paradidáticos. Ensino de Geografia.

\section{Como citar este documento - ABNT}

ALMEIDA, Jacqueline Praxedes de; CALAZANS, Denis Rocha. O que Cinderela e a Bela e a Fera têm a ver com a Geografia?. Revista Docência do Ensino Superior, Belo Horizonte, v. 9, e012547, p. 1-15, 2019. DOI: https://doi.org/10.35699/2237-5864.2019.12547.

Recebido em: 16/05/2019 Aprovado em: $17 / 07 / 2019$ Publicado em: 04/12/2019

\footnotetext{
${ }^{1}$ Universidade Federal de Alagoas (UFAL), Maceió, AL, Brasil. ORCID: https://orcid.org/0000-0001-7471-504X. E-mail: jacquepdealmeida@yahoo.com.br. 2 Instituto Federal de Alagoas (IFAL), Maceió, AL, Brasil.

ORCID: https://orcid.org/0000-0002-7996-4579. E-mail: denisrc1@yahoo.com.br.
} 


\section{¿QUÉ TIENEN QUE VER LA CENICIENTA Y LA BELLA Y LA BESTIA CON LA GEOGRAFÍA?}

\section{RESUMEN}

El uso de paradidácticos en las clases de Geografía ayuda a promover la interdisciplinariedad, además de posibilitar el estímulo al sentido crítico y a la ampliación de los conocimientos. En ese sentido, fue introducido en la disciplina de Metodología de la Enseñanza de Geografía, en el curso de Licenciatura en Geografía, el trabajo con obras literarias, más específicamente los cuentos infantiles, siendo éstos leídos y pensados en la perspectiva del trabajo con contenidos referentes al $2^{\circ}$ año del Nivel Medio. La actividad desarrollada tuvo como objetivo proporcionar a los estudiantes de Licenciatura bases para promover la integración entre Literatura y Geografía. El desarrollo de la actividad mostró, entre otros resultados, que la mayoría no había pensado en utilizar cuentos infantiles en las clases de Geografía y que, después de la ejecución de la actividad, adoptarían esta práctica durante las clases.

Palabras-clave: Formación docente. Libros paradidácticos. Enseñanza de Geografía.

\section{WHAT DOES CINDERELA AND BEAUTY AND THE BEAST GOT TO DO WITH GEOGRAPHY?}

\section{ABSTRACT}

The use of paradidactic in Geography classes helps to promote interdisciplinarity, beyond that, it stimulates critical thinking and the knowledge expansion. In this sense, it was introduced in the Geography Teaching Methodology, a discipline from the Geography Degree, some literary works, more specifically children's tales, read and thought from the perspective of second year of High School contents. The developed activity aimed to provide some bases to undergraduate students in order to promote the integration of Literature and Geography. The activity development demonstrates, among other results, that the majority of these students hadn't thought about using children's tales in geography classes and, after performing the proposed activity, they expressed support for adopting this practice in class.

Keywords: Teacher training. Books for educational purposes. Geography teaching. 


\section{INTRODUÇÃO}

Formar leitores é um grande desafio para a escola, devendo haver, por parte das instituições de ensino da educação básica, a promoção de ações "[...] que despertem nos alunos a valorização da leitura como instrumento para a aquisição do conhecimento, com vistas à sua emancipação e autonomia na sociedade" (HANSEM, 2012, p. 3). Nessa perspectiva, todo o corpo docente, incluindo o professor de Geografia, deve ter o compromisso de dinamizar os conhecimentos historicamente acumulados junto aos diferentes grupos de alunos, principalmente no que se refere ao aprofundamento do referencial que trata do caráter histórico e social da leitura como visão de mundo. Assim, é necessário que escola e professores se preocupem em promover o hábito da leitura como forma de aprimorar a interpretação textual, a reflexão, a criticidade, a argumentação e a aquisição de conhecimentos que ultrapassam os que estão nos livros didáticos.

Mais especificamente em relação ao diálogo entre a Geografia e a Literatura, pode-se afirmar que o "interesse dos geógrafos pela literatura não é novo" (BROSSEAU, 2007 apud FERNANDES, 2013, p. 170). Segundo o autor, há a presença da relação entre essas duas áreas do conhecimento nos estudos de Paul Vidal de La Blache e Humboldt. Mas foi somente na década de 1970, "[...] a partir do desenvolvimento das ideias associadas ao campo humanista que a relação entre a Geografia e a Literatura ganhou um novo fôlego" (FERNANDES, 2013, p. 171), passando a basear-se, entre outros aspectos, na transcrição da experiência dos lugares e na crítica social da realidade (BROSSEAU, 2007 apud FERNANDES, 2013). Nesse contexto, Castro (2016, p. 340) afirma que "imaginada como imitação da 'realidade', a literatura poderia oferecer à geografia uma espécie de 'cartografia do real', expressando, inclusive, determinada época, sociedade", assim, pode-se afirmar que a Literatura é relevante para a Geografia no sentido de resgatar, valorizar e apreender a experiência humana do espaço vivido nas obras literárias (OLANDA; ALMEIDA, 2008).

Mais especificamente no ensino da Geografia na educação básica, Azevedo e Almeida (2013, p. 140) ressaltam que "[...] em grande parte dos textos é possível realizar uma leitura com enfoque geográfico". Nesse sentido, pode-se afirmar que o diálogo da Geografia com a Literatura favorece não só o aprendizado, mas também a aplicação de metodologias diferenciadas que ajudam na compreensão do espaço geográfico (SALTORIS; CARDOSO, 2016).

As obras literárias podem ser produzidas sem uma intenção necessariamente didática, mas com potencial para serem utilizadas no ensino, ou podem ser produzidas propositadamente para esse fim (THOMSON, 2016). Independentemente de sua finalidade inicial, se possuem potencial para serem utilizadas como recursos no processo de ensino-aprendizagem, ambos os tipos de obras literárias podem ser classificados de paradidáticos. Portanto, neste trabalho, 
será encarado como livro paradidático toda obra literária com possibilidade de ser utilizada em sala de aula, incluindo a literatura infantil.

Diante do exposto, este trabalho, que se caracteriza como um relato de experiência, expõe a prática adotada na disciplina Metodologia do Ensino de Geografia, no curso de Geografia Licenciatura da Universidade Federal de Alagoas (UFAL). Nosso objetivo é mostrar o trabalho realizado com livros paradidáticos que podem ser usados no ensino da Geografia na educação básica, mais especificamente, contos infantis, bem como demonstrar as impressões, reflexões e descobertas feitas pelos licenciandos ao se depararem com a possibilidade de trabalhar com essas obras no Ensino Médio.

\section{OS PARADIDÁTICOS E O ENSINO DE GEOGRAFIA}

A utilização dos recursos didáticos em sala de aula pode ajudar na substituição de práticas docentes de enfoque tradicional e conteudista por outras que priorizem um ensino mais contextualizado, ético e participativo. Partindo da compreensão de que recurso didático é todo e qualquer material que, ao ser utilizado para fins pedagógicos, objetiva a melhoria na mediação no processo de ensino-aprendizagem, nesse rol incluem-se os livros paradidáticos (FISCARELLI, 2008; SILVA, 2015).

A denominação paradidático para os livros utilizados de forma paralela aos livros didáticos “[...] é uma invenção tipicamente brasileira: não que em outros países não existam livros que possam ser considerados 'paradidáticos', mas falta-lhes o nome" (MUNAKATA, 1997, p. 101). Os paradidáticos teriam tido sua origem na década de 1970 na Editora Ática, tendo ela criado a primeira coleção com o objetivo de apoiar, aprofundar conhecimentos e facilitar o processo de ensino-aprendizagem de conteúdos que muitas vezes são apresentados de forma enfadonha pelos livros didáticos (MUNAKATA, 1997, p. 101). Desse modo, os livros paradidáticos são materiais utilizados para serem trabalhados paralelamente com outros recursos, complementando os conteúdos trabalhados pelo docente, bem como serem suporte de aperfeiçoamento do próprio professor (SILVA, 2017).

Os livros paradidáticos são, segundo Souza (2013), obras que têm características próprias. Diferentemente dos livros didáticos, eles não seguem uma seriação e nem uma sequência de conteúdos conforme preconiza o currículo oficial, sendo eles geralmente adotados no processo de ensino e aprendizagem. Para Munakata (1997, p. 103), os

livros paradidáticos talvez sejam isso: livros que, sem apresentar características próprias dos didáticos (seriação, conteúdo segundo um currículo oficial ou não etc.), são adotados no processo de ensino e aprendizagem nas escolas, seja como material de consulta do 
professor, seja como material de pesquisa e de apoio às atividades do educando [...].

Ainda segundo o autor, "[...] o que define os livros paradidáticos é o seu uso como material que complementa (ou mesmo substitui) os livros didáticos" (MUNAKATA, 1997, p. 103). Nesse sentido, Cunha $(2009$, p. 3) afirma que esses "[...] livros têm por finalidade, principalmente na tradição escolar brasileira, de aprofundar uma temática, referente a um tópico específico de uma determinada disciplina escolar".

Pode-se afirmar que os paradidáticos são importantes para ajudar os professores a dinamizarem suas aulas e para complementar possíveis insuficiências dos livros didáticos, contribuindo no processo de ampliação e contextualização dos conhecimentos e, consequentemente, no processo de letramento científico, nesse sentido, a literatura "[...] ajuda na compreensão de questões quando outras expressões do humano não conseguem fazê-lo, como, às vezes, a linguagem da própria ciência" (TROCA; CHAIGAR, 2012, p. 159).

Maia (2011, p. 162) afirma que "[...] a literatura, mesmo constituindo uma disciplina ou um complemento da disciplina de língua portuguesa nos ensinos fundamental e médio, representa um importante campo de análise a ser explorado por vários campos do saber e, em especial, pela geografia". Assim, quando se trata da Geografia enquanto disciplina escolar, a Literatura também se faz presente, sendo um instrumento que contribui no processo de ensino-aprendizagem da Geografia, já que, através das obras literárias, o professor tem a oportunidade de favorecer, por exemplo, o entendimento das diferentes paisagens, regiões e aspectos sociais, políticos, econômicos e culturais em diferentes realidades temporais de uma forma mais dinâmica, sendo, portanto, "[...] a criação literária [...] um complemento altamente enriquecedor da Geografia [...]" (ORTEGA; PELOGGIA; SANTOS, 2009, p. 20).

Assim, pode-se afirmar que existe uma estreita relação entre o ensino da Geografia na educação básica e a Literatura. Segundo Silva e Barbosa (2014, p. 80), o ensino da Geografia “[...] pela literatura promove a ampliação das concepções conceituais e categóricas para os estudantes ao mesmo tempo que estimula nova linguagem e, portanto, promove o desenvolvimento da capacidade crítica nos alunos [...]".

Para Fernandes (2010), é importante destacar que a escolha de um livro paradidático, objetivando o aprofundamento de um tema, deve ser uma opção do professor. É ele que deve escolher e destacar o tema que terá um estudo mais apurado e, por consequência, qual obra melhor se enquadra na temática escolhida, bem como o que melhor se adequa à faixa etária de quem irá lê-lo. Para tanto, o professor precisa estar preparado para saber escolher o livro paradidático que irá utilizar em sala de aula com seus alunos. 
Apesar das potencialidades do uso dos paradidáticos no ensino da Geografia na educação básica, "cabe destacar que os livros paradidáticos são materiais que praticamente não são utilizados pelos docentes de Geografia. Embora saibam da existência deles no contexto escolar e de suas possibilidades de uso, ainda não conseguem inseri-los no ambiente de sala de aula" (SILVA, 2017, p. 8), havendo, portanto, a necessidade de que, ainda em seu processo de formação inicial, os futuros professores possam ser embasados para a escolha e para o uso dos paradidáticos em sua prática em sala de aula.

\section{DESCREVENDO A PRÁTICA}

Visando preparar os futuros docentes para trabalhar Geografia e Literatura em sala de aula, foi introduzido na disciplina de Metodologia do Ensino de Geografia, no curso de Licenciatura em Geografia da UFAL, no ano letivo de 2018, o trabalho com contos infantis, sendo esses contos lidos e pensados na perspectiva do trabalho com conteúdos referentes ao Ensino Médio, mais especificamente com o 2 ㅇ ano dessa etapa da educação básica. $O$ trabalho foi desenvolvido com quatro turmas, totalizando 41 alunos do 4 ㅇ período dos turnos vespertino e noturno.

A atividade foi realizada em etapas. A primeira etapa constituiu-se em fazer a leitura dos contos infantis. Foram trabalhados com os licenciandos quatro contos infantis, sendo eles: $\mathrm{A}$ Bela e a Fera, Cinderela, A Bela Adormecida e João e Maria. Essa primeira ação teve por objetivo ambientar os licenciandos à narrativa dos contos infantis e estimulá-los a identificar conteúdos geográficos nas histórias.

A segunda etapa foi a leitura de duas reportagens, uma da Revista Superinteressante e a outra da Revista Visão História, de publicação portuguesa. O uso das reportagens, logo após a leitura dos contos infantis, teve como objetivo situar os licenciandos na realidade histórica e nos aspectos sociais, econômicos e culturais da época em que as narrativas foram escritas, para que, dessa forma, eles iniciassem um processo de ampliação da visão dos conteúdos geográficos presentes nos contos.

A terceira e última etapa foi a leitura do livro didático Território e Sociedade no Mundo Globalizado, da Editora Saraiva e de autoria de Elian Alabi Lucci, Anselmo Lazzaro Branco e Cláudio Mendonça. A leitura do livro didático teve como objetivo levar os alunos a identificarem os assuntos tratados no livro com a realidade descrita nos contos e nas reportagens, bem como fazê-los perceber que, apesar de serem fontes, abordagens e estilos diferentes, as temáticas estavam presentes em todos os materiais utilizados na atividade.

Antes de iniciar a atividade, as turmas foram divididas em quatro grupos, cada um composto de duas a três pessoas. Posteriormente, cada grupo recebeu um livro infantil diferente dos 
demais e a cada etapa do processo de leitura eram feitas perguntas aos licenciandos. Foram feitas 6 perguntas. $O$ primeiro e segundo questionamento feitos logo após a leitura do conto infantil foram: 1) O grupo já conhecia essa história infantil? e 2) O que (nome da história infantil) tem a ver com a Geografia? O terceiro questionamento, após a leitura da reportagem, foi: 3) Depois da leitura da reportagem, sua visão permaneceu a mesma, mudou ou ampliou? Justifique. O quarto questionamento ocorreu após a leitura do livro didático: 4) Após a leitura do livro didático, sua visão permaneceu a mesma, mudou ou ampliou? Justifique. As demais perguntas foram feitas após todas as leituras, sendo elas: 5) Após as leituras, vocês levariam contos infantis para as aulas de Geografia? Justifique. 6) Em algum momento anterior a essa atividade, vocês pensaram em levar um conto infantil para sala de aula para trabalhar assuntos de Geografia? Todas as respostas deveriam ser registradas em papel sulfite, previamente entregue aos grupos. Vale ressaltar que cada grupo não sabia quais eram as leituras que os demais estavam fazendo. Ao final da atividade, socializaram com os demais colegas suas leituras, impressões e reflexões sobre os materiais lidos.

O objetivo da atividade foi proporcionar aos licenciandos, além do conhecimento, a possibilidade de integração entre Literatura e Geografia e o desenvolvimento da percepção de que essa integração é ampla e pode ser feita utilizando as mais diversas obras literárias, incluindo as histórias infantis, enfocando que, para tanto, se faz premente o domínio dos conhecimentos referentes à sua área de atuação, pois, como afirma Nóvoa (2016, p. 1), "não se pode ser professor sem [...] saber muito bem o conteúdo que se vai ensinar - isso é central, se não se souber muito bem história, não se pode ensinar história; se não se souber muito bem matemática, não se pode ensinar matemática" e isso inclui a Geografia.

\section{ENXERGANDO POTENCIALIDADES GEOGRÁFICAS NOS CONTOS INFANTIS}

Assim como na vida pessoal, a Literatura assume uma significativa importância na sala de aula, dada sua capacidade de ampliar a visão de mundo do indivíduo e de auxiliar no desenvolvimento da linguagem. Nessa perspectiva, "[...] emerge a relação entre Geografia e Literatura como uma forma de promoção da interdisciplinaridade, além de ser uma possibilidade de se utilizar uma manifestação artística para estimular o senso crítico e um (re)conhecimento da realidade do aluno em outros contextos de vivência que não o seu próprio" (BERALDI, 2011, p. 2). Beraldi (2011) ainda complementa afirmando que a Geografia que se busca, ao se trabalhar em conjunto com a Literatura, é aquela que não se limita a pensar dentro dos pressupostos cartesianos, onde há uma hipótese, que carece de ser testada dentro de parâmetros pré-estabelecidos, para ser comprovada ou refutada. Ao se analisar uma obra literária tendo em mente a construção da linguagem geográfica em diferentes contextos, é possível que se faça uma atividade libertadora de pensar o espaço a partir de 
uma leitura que não é somente racional, mas também é atividade que envolve os sentidos, a razão e a emoção.

Segundo Cavalcanti (2013, p. 110), na educação infantil, os contos tradicionais, como os contos de fadas, "[...] ocupam um lugar relevante, por serem as primeiras narrativas literárias com as quais as crianças têm contato frequente". Ainda segundo a autora, a origem desses contos é oral e de uma época indefinida, mas "[...] manter as novas gerações em contato com esses textos contribui para perpetuar a tradição de contar histórias [...] e garante a transmissão dos enredos de diferentes culturas, que fazem parte do imaginário de tantos povos há séculos" (CAVALCANTI, 2013, p. 109).

Nos contos infantis pode-se encontrar um grande leque de temas, personagens, tramas e ambientes que ajudam o leitor a mergulhar no que há de mais complexo na humanidade (CAVALCANTI, 2013, p. 109). Nessa perspectiva, se pensou no desenvolvimento de uma atividade, a ser empregada com os licenciandos de Geografia, utilizando a "literatura infantil, a qual aparentemente não tem relação com aquilo que se convencionou chamar de conteúdo geográfico" (FERRAZ; BERALDI, 2013, p. 177), como forma de ampliar o olhar e o pensar dos futuros professores para o uso da Literatura nas aulas de Geografia no Ensino Médio.

O primeiro ponto que chamou a atenção no desenvolvimento da atividade com os licenciandos foi o desconhecimento de parte deles de algumas histórias infantis, dentre elas Rapunzel, história não utilizada na dinâmica e que foi comentada nas conversas que ocorreram durante a ação, e o conto de João e Maria, que compôs a atividade.

Ao fazer a análise das respostas dos grupos em relação à segunda pergunta, que buscou identificar quais as relações que eles faziam entre os contos infantis e a Geografia, verificouse que um dos grupos não conseguiu fazer nenhuma relação com a Geografia, os demais reconheceram parcialmente os conteúdos geográficos que poderiam ser trabalhados na educação básica. As respostas dos grupos se concentraram na indicação da possiblidade de trabalho com os assuntos relacionados aos aspectos físicos, mais precisamente à vegetação, ao clima e à cartografia, esse último focando nos conteúdos de orientação e localização e nas categorias da Geografia, sendo citados por eles lugar, paisagem e território (no sentido de limite territorial de um país).

As respostas dos licenciandos a essa segunda questão nos remete a Ferraz e Beraldi (2013, p. 179), quando alegam que o que se entende, na maioria das vezes, como geográfico é, por exemplo, "[...] a caracterização das diferentes estações climáticas do ano [...], exemplificar o que seria lago ou determinada vegetação", ou ainda a Souza, Santos e Mendes (2011, p. 5), ao afirmarem que o estudo da Geografia deve transcender "[...] as informações sobre os 
limites políticos dos territórios mundiais e as nomenclaturas dos mapas como sendo os temas mais curiosos e pertinentes dessa ciência [...]".

Assim, percebe-se nesse primeiro momento que os licenciandos estavam distantes do poder crítico que temas abordados pela Geografia podem ter, a exemplo "[...] dos debates sociais segundo as necessidades da população em seu tempo histórico, assim como, a influência do sistema econômico capitalista e das diversidades das relações que tal organização econômica impõe às redes estabelecidas entre o global e o local, entre outros debates imprescindíveis à formação crítica e geográfica dos sujeitos" (SOUZA; SANTOS; MENDES, 2011, p. 5). Essas primeiras respostas se colocam ainda distantes da abordagem, na Geografia, de "[...] temas contemporâneos que afetam a vida humana em escala local, regional e global [...]" (BRASIL, 2017, p. 19), concebendo, assim, uma articulação dessa disciplina com os "temas transversais" propostos pela Base Nacional Comum Curricular (BNCC).

A articulação da Geografia com assuntos debatidos na atualidade suscita a possibilidade de um encadeamento dessa disciplina com a questão, por exemplo, da diversidade associada aos temas transversais Educação em Direitos Humanos e Diversidade Cultural, objetivando "[...] exercitar o respeito às diferenças entre os indivíduos [...]" (FERRAZ; BERALDI, 2013, p. 179). A partir dessa compreensão, a Geografia no Ensino Médio atenderia à competência, explicitada na BNCC para as Ciências Humanas, de identificar e combater as diversas formas de injustiça, preconceito e violência, adotando princípios éticos, democráticos, inclusivos e solidários, respeitando os Direitos Humanos. Essa competência teria como finalidade, através do

[...] exercício de reflexão, [...] [permitir] aos jovens compreender os fundamentos da ética em diferentes culturas, estimulando o respeito às diferenças (linguísticas, culturais, religiosas, étnico-raciais etc.), à cidadania e aos Direitos Humanos. Ao realizar esse exercício na abordagem de circunstâncias da vida cotidiana, os estudantes podem desnaturalizar condutas, relativizar costumes e perceber a desigualdade, o preconceito e a discriminação presentes em atitudes, gestos e silenciamentos, avaliando as ambiguidades e contradições presentes em políticas públicas tanto de âmbito nacional como internacional (BRASIL, 2017, p. 577).

A partir da concepção exposta, os licenciandos foram levados a ler as duas reportagens das revistas. A primeira, intitulada "O lado sombrio dos contos infantis", que descreve a realidade histórico-cultural europeia vivenciada pelos autores no período da criação/adaptação dos contos infantis lidos pelos licenciandos, menciona questões ligadas à conduta social, à desigualdade de gênero e ao comportamento demográfico. A segunda, intitulada "De pé, ó vítimas da fome", apresenta questões ligadas à produção agrícola, escassez de alimentos, fome e prática social do canibalismo, situação ligada diretamente ao hábito alimentar da bruxa do conto de João e Maria. Após essas leituras, buscou-se saber se a visão dos alunos 
sobre os aspectos geográficos nos contos infantis permanecia a mesma, se tinha mudado ou se havia ampliado. A maioria dos grupos, exceto um, afirmou que a visão de seus integrantes sobre a relação dos contos infantis com o ensino da Geografia foi ampliada, estando presente nas respostas dos licenciandos o acréscimo de outros elementos como a possibilidade da interdisciplinaridade, de relacionar os fatos do passado com os do presente e o acréscimo de temas ligados à cultura, à sociedade e à economia.

$\mathrm{Na}$ terceira etapa da atividade, a leitura dos licenciandos foi direcionada para partes específicas do livro didático, que abordam temas como: crescimento populacional e teorias demográficas; Revolução Industrial e crescimento Populacional; crescimento da população no século XX; desigualdade entre gêneros; população e recursos naturais; fome e subnutrição; expectativa de vida da população por sexo; atividade agropecuária e Revolução Agrícola e Revolução Verde. Essa ação teve o objetivo de levar os alunos a perceberem as relações existentes entre os elementos dos contos infantis e os assuntos tratados nos livros didáticos. Após as leituras, os grupos foram questionados se a visão deles sobre o uso dos contos infantis nas aulas de Geografia permanecia a mesma, se havia mudado ou se havia ampliado. Três dos quatro grupos afirmaram que a visão deles em relação à utilização dos contos infantis nas aulas de Geografia foi ampliada. As respostas dadas pelos licenciandos mostraram que eles perceberam que os assuntos tratados pela Geografia no livro didático estão presentes nas histórias infantis. Isso fica evidente quando justificam suas respostas afirmando que poderiam trabalhar, a partir dos contos, com o grau de desenvolvimento dos países; aspectos socioculturais e relações de gênero. Um aspecto importante das respostas foi a sugestão de que o uso do livro didático ou paradidático fosse complementado com outras ações, principalmente no que se refere à Geografia e Gênero, podendo trazer para a escola palestras e relatos de experiências que abordem os temas mais delicados, socializando informações que ajudem na prevenção de abusos e facilitem denúncias.

A proposta dessa postura educativa coaduna com as ideias de Souza, Santos e Mendes (2011, p. 6), quando afirmam que "cabe ao professor ser articulador de novas opiniões [...] instigando o aluno a ser um sujeito capaz de pensar sobre qualquer polêmica de seu tempo e realidade, de forma a propor soluções por meio de reivindicações asseguradas na lei". Os resultados dessa etapa também se relacionam ao que Pontuschka, Paganelli e Cacete $(2007$, p. 264) defendem, quando afirmam que a Geografia, enquanto disciplina escolar, "[...] deve propiciar ao aluno a leitura e a compreensão do espaço geográfico como uma construção históricosocial, fruto das relações estabelecidas entre sociedade e natureza".

Após a realização das etapas anteriores, foi perguntado se os licenciandos usariam contos infantis nas aulas de Geografia. Todos responderam que sim, justificando que as histórias infantis ajudariam a ilustrar algumas temáticas da Geografia, bem como poderiam usar a 
história como fio condutor da sequência de assuntos ao longo da aula. Afirmaram também que os contos poderiam auxiliar na abordagem de temas mais complexos, possibilitando ainda aprofundar assuntos já trabalhados a partir da identificação deles nos contos infantis.

Ao responder a última pergunta, que buscou saber se eles já haviam pensado em levar um conto infantil para trabalhar conteúdos geográficos na educação básica, apenas um grupo afirmou que já havia pensado em usar contos infantis nas aulas dessa disciplina, mas que, até então, não saberia como fazê-lo. Os demais grupos afirmaram que não tinham pensado nisso, justificando que, até o momento da realização da atividade, nunca tinham relacionado os contos à Geografia.

\section{CONSIDERAÇÕES FINAIS}

A diversidade de materiais literários que pode ser utilizada com os alunos da educação básica nas aulas de Geografia é ampla, e nesse rol estão inseridos os contos infantis. Mas para que essa produção literária faça parte das aulas dessa disciplina, é necessário que os professores não sejam apenas leitores e agentes de estímulo à leitura e à reflexão, mas também que saibam como utilizar essas obras em sala de aula. Para isso, é necessário que o processo de formação acadêmica contemple a instrumentalização do licenciando para o trabalho pedagógico associando a Literatura e a Geografia, mostrando possibilidades de abordagens temáticas e de interdisciplinaridade.

O trabalho aqui relatado mostra a importância de os cursos de licenciatura proporcionarem a preparação ao futuro professor para as múltiplas possibilidades pedagógicas, cabendo aos docentes dos cursos de formação de professores inserir nas suas aulas momentos de aprendizagem e sensibilização, no intuito de auxiliar os licenciandos na construção de uma futura práxis que contemple, entre outros recursos de ensino, o uso da Literatura nas aulas de Geografia.

O uso de contos infantis como paradidáticos possibilita a aplicação de uma prática educativa que favorece a compreensão do espaço geográfico, promovendo a análise e o entendimento de diferentes ramos da Geografia. Neste trabalho, os professores em formação foram estimulados a assumir uma postura ativa para a compreensão dos porquês das situações narradas nas histórias.

Nesse sentido, o trabalho conduziu os licenciandos a desenvolver um olhar que percebe aspectos geográficos que estão menos explícitos nas histórias, o que possibilita, aos professores em formação, o exercício de um olhar mais amplo sobre o uso dos paradidáticos nas aulas de Geografia, extrapolando a visão tradicional dessa disciplina e permitindo um 
pensar o espaço geográfico a partir de uma leitura que não é somente racional, mas também é atividade que envolve os sentidos e a emoção.

O trabalho prático de leitura de contos infantis, sua análise crítica, o auxílio de reportagens sobre temáticas tratadas pela Geografia na Literatura e a confrontação dessas informações com o conteúdo dos livros didáticos mostraram que é necessário, mas também relativamente fácil, despertar nos futuros professores novas formas de se trabalhar a Geografia, tornandoos mais habilitados para desenvolver atividades educativas capazes de ampliar a percepção dos alunos sobre o espaço geográfico. É esse tipo de formação inicial que dará aos educadores subsídios para colocar em prática uma educação de qualidade, aptos a contribuir com a formação de alunos críticos, capazes de interpretar a realidade nos diversos tempos históricos e nos diversos meios em que se apresente.

\section{REFERÊNCIAS}

A BELA adormecida. Itapevi: Ciranda Cultural Editora e Distribuidora, 2011.

A BELA e a fera. Itapevi: Ciranda Cultural Editora e Distribuidora, 2011.

AZEVEDO, Sandra de Castro de; ALMEIDA, Cilene Gomes Brito de. O paradidático como instrumento facilitador no ensino de geografia. Revista de Ensino de Geografia, Uberlândia, v. 4, n. 6, p. 139-148, jan./jun., 2013. Disponível em:

http://www.revistaensinogeografia.ig.ufu.br/N.6/Rel1av4n6.pdf. Acesso em: 23 maio 2018.

BERALDI, Francielle Bonfim. Geografia e literatura infantil: a construção da linguagem geográfica através de textos literários nas séries iniciais do ensino fundamental. In: SEMANA DE GEOGRAFIA, 12., 2011, Presidente Prudente. Anais [...] Presidente Prudente: UNESP, 2011. p. 1-11. Disponível em:

http://www2.fct.unesp.br/semanas/geografia/2011/ensinodegeografiaeepistemologia/TCE G01\%20-\%20Francielle\%20Bonfim\%20Beraldi.pdf. Acesso em: 25 maio 2018.

BRASIL. Base Nacional Comum Curricular. Brasília: MEC, 2017. Disponível em:

http://basenacionalcomum.mec.gov.br/images/BNCC_EI_EF_110518_versaofinal_site.pdf. Acesso em: 23 janeiro 2019.

CASTRO Júlia Fonseca. Geografia e literatura: da aproximação ao diálogo. In: SUZUKI, Júlio César; LIMA, Angelita Pereira; CHAVEIRO, Eguimar Felício (org.). Geografia, literatura e arte: epistemologia, crítica e interlocuções [livro eletrônico]. Porto Alegre: Imprensa Livre, 2016.

CAVALCANTI, Zélia. Caderno de Leituras: orientações para o trabalho em sala de aula. São Paulo: Companhia das Letras, 2013.

CINDERELA. Itapevi: Ciranda Cultural Editora e Distribuidora, 2011. 
CUNHA, André Victor Cavalcanti Seal da. Livros didáticos de história: uma análise das apropriações pela prática pedagógica dos professores. In: SIMPÓSIO NACIONAL DE HISTÓRIA, 25., 2009, Fortaleza. Anais [...] Fortaleza: UFC, 2009. p. 1-11. Disponível em: http://anais.anpuh.org/wp-content/uploads/mp/pdf/ANPUH.S25.1414.pdf. Acesso em: 23 maio 2018.

FISCARELLI, Rosilene Batista de Oliveira. Material didático: discurso e saberes. Araraquara: Junqueira \& Martins Editoras, 2008.

FERNANDES, Bernardo Mançano. O livro paradidático em sala de aula: do planejamento ao uso. In: CASTROGIOVANNI, Antonio C. (org.). Geografia em sala de aula: práticas e reflexões. 5. ed. Porto Alegre: Editora da UFRGS, 2010. p.151-156.

FERNANDES, Felipe Moura. Geografia e literatura (ciência e arte): Proposições para um diálogo. Espaço e Cultura, Rio de Janeiro, n. 33, p.167-176, jan./jun. 2013.

FERRAZ, Cláudio Benito O.; BERALDI, Francielle Bonfim. Geografia e Literatura Infantil: considerações para devires minoritários da educação. In: PORTUGAL, Jussara Fraga; OLIVEIRA, Simone Santos; PEREIRA, Tânia Regina Dias Silva (org.). Geografias e linguagens: concepções, pesquisas e experiências formativas. Curitiba: CRV, 2013. p. 165-188.

HANSEM, Marilene do Carmo. A leitura como instrumento para a aquisição do conhecimento. In: O professor PDE e os desafios da escola pública paranaense. Curitiba: Secretaria da Educação, 2012.

HUECK, Karin. O lado sombrio dos contos de fadas. Superinteressante, São Paulo: Editora Abril, ano 30, n. 12, p. 24-33, 2017.

JOÃO e Maria. Itapevi: Ciranda Cultural Editora e Distribuidora, 2011.

LUCCI, Elian Alabi; BRANCO, Lazaro Anselmo; MENDONÇA, Cláudio. Território e sociedade no mundo globalizado, Ensino Médio. 3. ed. São Paulo: Saraiva, 2016. v. 2.

LUCCI, Elian Alabi; BRANCO, Lazaro Anselmo; MENDONÇA, Cláudio. Território e sociedade no mundo globalizado, Ensino Médio. 3. ed. São Paulo: Saraiva, 2016. 3 v.

MAIA, Doralice Sátyro. Uma leitura geográfica da obra de José Lins do Rego: aproximando a literatura do ensino de geografia. In: REGO, Nelson; CASTROGIOVANNI, Antonio Carlos; KAERCHER, Nestor André (org.). Geografia: práticas pedagógicas para o ensino médio. Porto Alegre: Penso, 2011.

MARTINS, Luís Almeida. De pé, ó vítimas da fome. Visão História, Paço de Arcos: Medipress, n. 28, p. 48-51, abr. 2015. 
MUNAKATA, Kazumi. Produzindo Livros Didáticos e Paradidáticos. 1997. 218 f. Tese (Doutorado em Educação) - Programa de Pós-Graduação em História e Filosofia da Educação, Pontifícia Universidade Católica de São Paulo, São Paulo, 1997.

NÓVOA, António. O lugar da licenciatura. Revista Educação. 2016. Disponível em: http://www.revistaeducacao.com.br/o-lugar-da-licenciatura/. Acesso em: 23 maio 2018.

OLANDA, Diva Aparecida Machado; ALMEIDA, Maria Geralda. A geografia e a literatura: uma reflexão. Geosul, Florianópolis, v. 23, n. 46, p 7-32, jul./dez. 2008.

ORTEGA, Any Marise; PELOGGIA, Alex Ubiratan Goossens; SANTOS, Fábio Cardoso. A Literatura no caminho da História e da Geografia: Práticas integradas com a Língua Portuguesa. São Paulo: Cortez, 2009.

PONTUSCHKA, Nídia Nacib; PAGANELLI, Tomoko lyda; CACETE, Núria Hanglei. Para ensinar e aprender Geografia. São Paulo: Cortez, 2007.

SALTORIS, Daiala Barroso; CARDOSO, Cristiane. Geografia e Literatura: uma proposta para um ensino interdisciplinar. In: ENCONTRO NACIONAL DE GEÓGRAFOS, 18., 2016, São Luís. Anais [...] São Luís: UFMA, 2016. p. 1-12. Disponível em:

http://www.eng2016.agb.org.br/resources/anais/7/1467662012_ARQUIVO_ArtigoENG.pdf. Acesso em: 23 maio 2018.

SILVA, Igor Antônio; BARBOSA, Tulio. O ensino de geografia e a literatura: uma contribuição estética. Caminhos de Geografia. Uberlândia v. 15, n. 49, p. 80-89, mar., 2014.

SILVA, Izabel Cristina. Livro paradidático: uma porta aberta para o ensino de Geografia Universidade Federal do Rio Grande do Norte. 2017. 244 f. Dissertação (Mestrado Profissional em Geografia) - Universidade Federal do Rio Grande do Norte, Caicó, 2017.

SILVA, Luciana Bessa. O trabalho docente com livros paradidáticos no ensino médio. In: CONGRESSO NACIONAL DE EDUCAÇÃO, 2., 2015, Campina Grande. Anais [...] Campina Grande: Centro de Convenções Raymundo Asfora, 2015. p. 1-11. Disponível em: http://www.editorarealize.com.br/revistas/conedu/trabalhos/TRABALHO_EV045_MD1_SA1 5_ID1210_27072015165013.pdf. Acesso em: 23 maio 2018.

SOUZA, Josemir da Paixão de. Uma introdução dos livros paradidáticos no ensino de matemática. In: CONGRESSO INTERNACIONAL DE ENSINO DE MATEMÁTICA, 6., 2013, Canoas. Anais [...] Canoa: ULBRA, 2013. p. 1-13.

SOUZA, Fernanda Dione Sales; SANTOS, Sandra Maria Oliveira; MENDES, Geisa Flores. A prática docente do profissional de Geografia no Instituto de Educação Euclides Dantas (IEED) em Vitória da Conquista - BA. In: ENCONTRO BAIANO DE GEOGRAFIA/X SEMANA DE GEOGRAFIA DA UESB, 8., 2011, Vitória da Conquista. Anais [...] Vitória da Conquista: UESB, 2011. p. 1-18. Disponível em: http://www.uesb.br/eventos/ebg/anais/3a.pdf. Acesso em: 23 maio 2018. 
THOMSON, Ana Beatriz Accorsi. Os paradidáticos no ensino de História: uma reflexão sobre a literatura infantil/juvenil na atualidade. Revista do Lhiste. Porto Alegre, v. 3, n. 4, p. 27-49, jan/jun. 2016.

TROCA, Renata Ávila; CHAIGAR, Vânia Alves. Literatura, história de vida e o ensino da vida das Geografias do "fim do mundo". In: PORTUGAL, Jussara Fraga; CHAIGAR, Vânia Alves Martins (org.). Cartografia, cinema, literatura e outras linguagens no ensino de Geografia. Curitiba: CRV, 2012. p. 157-171.

\section{Jacqueline Praxedes de Almeida}

Foi professora da educação básica da rede pública e particular. Atualmente é professora Adjunta do Curso de Geografia Licenciatura da Universidade Federal de Alagoas, coordenando o PIBID Geografia. Doutora e mestra em Ciências da Educação pela Universidade de Évora (2014 e 2007), especialista em Psicopedagogia no Cotidiano Escolar pela Unigranrio (1997) e graduada em Geografia Licenciatura pela Universidade Federal de Alagoas (1995).

jacquepdealmeida@yahoo.com.br

\section{Denis Rocha Calazans}

Possui graduação em Geografia Bacharelado e Licenciatura pela Universidade Federal de Alagoas (1995 e 2005), especialização em Docência do Ensino Superior (2007), mestrado em Recursos Hídricos e Saneamento pela Universidade Federal de Alagoas (2014) e é doutorando em Educação pela Universidade Tecnológica Intercontinental (UTIC). Atualmente é professor do Instituto Federal de Alagoas (IFAL).

denisrc1@yahoo.com.br. 